\title{
Desenvolvimento regional no Vale do Taquari-RS: uma discussão de prioridades estratégicas $^{1}$
}

\author{
Cintia Agostini \\ Centro Universitário Univates
}

Recebido: 13/05/2015 Versão revisada (entregue): 08/08/2015 Aprovado: 18/08/2015

\begin{abstract}
Resumo
O presente artigo discute as prioridades estratégicas do Vale do Taquari-RS e sua relação com o movimento de globalização. Parte do princípio de que há uma relação contraditória entre a construção das regiões e a ação hegemônica, mas avalia que é nos territórios que todos os atores atuam, sejam eles pertencentes à lógica global ou aqueles considerados contra hegemônicos. Nestas condições, conceber o desenvolvimento é considerar o regional e o global em interação dialética, levando em conta o passado e construindo as perspectivas de cada região. Metodologicamente, o artigo resulta de uma pesquisa descritiva qualitativa, com levantamento de dados bibliográficos e documentais. Através da análise de conteúdo avaliam-se diversas prioridades apontadas pelos atores regionais e se infere sobre sua relação com a lógica mundial. $\mathrm{O}$ artigo encerra destacando que a região, sob a perspectiva proposta, não demonstra ser a mais atrelada à lógica global; mas, o olhar das particularidades regionais ainda se resume aos aspectos de qualidade de vida da população e não avança para outros, que são fundamentais na regionalização de um território.
\end{abstract}

Palavras-chave | Desenvolvimento regional; globalização; prioridades estratégicas; Vale do Taquari-RS.

Código JEL | O18; R11; R58.

\section{REGIONAL DEVELOPMENT IN THE TAQUARI VALLEY-RS: A DISCUSSION OF STRATEGIC PRIORITIES}

\begin{abstract}
This article discusses the strategic priorities on the Taquari Valley-Rio Grande do Sul State (Brazil) and its relation to the movement of globalization. It assumes that there is a contradictory relationship between the construction of the regions and the hegemonic action, but it says that in the territories all actors act, whether belonging to the global logic or those,

\footnotetext{
${ }^{1}$ Uma primeira versão deste artigo foi apresentada no IX Encontro de Economia Catarinense, que ocorreu nos dias 7 e 8 de maio de 2015, na Unochapecó, em Chapecó/SC.
} 
which can be considered against hegemonic. Under these conditions, designing development is to consider the regional and global in the dialectic condition of being, taking into account the past and building the perspectives of each region. Methodologically this is a qualitative descriptive research, a survey of bibliographic and documentary data. Through content analysis, it evaluates several priorities identified by regional actors and infers about its relationship with the global logic. Finally it highlights that the region, under the proposal perspective, do not shows to be more linked to global logic, but the look of the regional particularities still comes down to the quality aspects of life of the population and does not proceed to others which are instrumental in regionalization of a territory.

Keywords | Globalization; regional development; strategic priorities; Taquari Valley-RS.

JEL-Code | O18; R11; R58.

\section{DESARROLLO REGIONAL EN EL VALLE DEL TAQUARI-RS: UNA DISCUSIÓN DE LAS PRIORIDADES ESTRATÉGICAS}

\section{Resumen}

Este artículo aborda las prioridades estratégicas del Valle del Taquari-Estado de Rio Grande do Sul (Brasil) y su relación con el movimiento de la globalización. Se supone que existe una relación contradictoria entre la construcción de las regiones y la acción hegemónica, pero dice que es en los territorios que todos los actores actúan, ya que pertenece a la lógica global o aquellos que se pueden considerar contra hegemónica. En estas condiciones, el desarrollo del diseño, es considerar lo regional y lo mundial en la condición dialéctica del ser, teniendo en cuenta el pasado y la construcción de la perspectiva de cada región. Metodológicamente se trata de una investigación descriptiva cualitativa, un estudio de los datos bibliográficos y documentales y mediante el análisis de contenido, evalúa varias prioridades identificadas por los actores regionales y infiere sobre su relación con la lógica global. Cierra señalando que la región, bajo la perspectiva de la propuesta, no demuestra estar más ligada a la lógica global, pero la mirada de las particularidades regionales aún se reduce a los aspectos de la calidad de vida de la población y no avanza a otros que son instrumentales en la regionalización de un territorio.

Palabras-clave | Desarrollo regional; globalización; prioridades estratégicas; Valle del TaquariRS.

Código JEL | O18; R11; R58.

\section{Introdução}

Regiões são expressões de arranjos territoriais particulares e a regionalização é a construção do próprio processo, das particularidades na interação com a totalidade. Nestas condições, o desenvolvimento regional se dá a partir das ações nos territórios construídos, apropriados pela sociedade, ou seja, é no território que se identificam regiões ou lugares.

Para tanto, Etges (2005, p. 54) afirma que "um território só existe a partir da materialidade que lhe é dada pelo seu uso" e é dessa forma que ocorre o processo 
de regionalização, que possibilita a formação de uma região com base em um território. Enfatiza que os territórios possuem uma conformação a partir das condições naturais, e, no entanto, não são essas que determinam a região, porque "este uso é determinado por interesses econômicos, sociais, políticos e culturais. São estes, portanto, os aspectos que definem uma região nos dias atuais." (ETGES, 2001, p. 353).

Nestas condições, o presente artigo propõe discutir a relação dialética do movimento da globalização e da construção das regiões, considerando que é no território que todos atuam concretamente e onde o movimento contra hegemônico poderá ocorrer. $\mathrm{Na}$ sequência, discute a construção da região a partir da percepção do processo de regionalização, considerando que a região é resultado de arranjos territoriais particulares no contexto dinâmico mundial.

A partir desta percepção teórica, este artigo traz à discussão documentos considerados estratégicos para o Vale do Taquari, os quais indicam prioridades regionais, articuladas em diferentes instâncias, com objetivos diversos no transcurso do tempo. Além de discorrer sobre as características regionais, analisa os temas trazidos nestes documentos. Por fim, encerra discutindo as possibilidades de um desenvolvimento regional no Vale do Taquari, considerando as prioridades estratégicas identificadas, na relação dialética da região com o movimento da globalização.

Para possibilitar a discussão, conforme indicada nesta introdução, metodologicamente esta é uma pesquisa qualitativa descritiva, considerando que a abordagem qualitativa busca "compreender os sistemas de significados utilizados por um grupo ou uma sociedade." (BAQUERO et al, 1995, p. 21). Ainda, é uma pesquisa descritiva, pois descreve o tema a partir da aproximação, ou seja, "quando o pesquisador apenas registra e descreve os fatos observados sem interferir neles. Visa a descrever as características de determinada população ou fenômeno ou o estabelecimento de relações entre variáveis." (PRODANOV e FREITAS, 2013, p. 52). Neste contexto, o artigo busca compreender as relações da região do Vale do Taquari, as estratégias e as prioridades regionais e sua relação com o movimento global.

Relevante salientar que, considerando o procedimento de coleta de dados, foi necessário "descrever a situação do contexto em que está sendo feita determinada investigação." (GIL, 1999, p. 73). Como situação contexto, temos as especificidades regionais e, mais precisamente, o território onde o estudo está sendo proposto. A região de abrangência da presente pesquisa é o Vale do Taquari, no estado do Rio Grande do Sul.

Já a coleta de dados se deu a partir de dados bibliográficos e documentais. Enquanto pesquisa bibliográfica, "na atualidade, praticamente qualquer necessidade humana, conhecida ou pressentida, tem algo escrito a seu respeito. Por isso, a pesquisa com base em uma bibliografia deve encabeçar qualquer 
processo de busca científica que se inicie." (SANTOS, 2007, p. 30). Considera-se essencial a pesquisa bibliográfica "à construção do objeto de pesquisa e como tal deve ser tratado" (ALVES, 1992, p. 58) e é nestas condições que foram analisadas referências que deram conta de aprofundar o conhecimento e possibilitaram "o desenvolvimento teórico-metodológico" do artigo (ALVES, 1992, p. 58).

Também foram feitas pesquisas nos documentos publicados pelas entidades regionais, citados ao longo do texto. Foi considerado que "documento é o nome genérico dado às fontes de informação bibliográficas que ainda não receberam organização, tratamento analítico e para publicação." (SANTOS, 2007, p. 32).

Por fim, o tratamento dos dados foi feito através de análise de conteúdo, pois esta "é considerada uma técnica para o tratamento de dados que visa identificar o que está sendo dito a respeito de determinado tema." (VERGARA, 2005, p. 15). Assim, todos os dados coletados qualitativamente, sejam eles bibliográficos ou documentais, foram avaliados nestas condições.

\section{A relação dialética entre a região e o movimento global}

O modo de produção capitalista, que se consolida enquanto tal entre os séculos XVI e XVII, busca diferentes e diversas formas para viabilizar seus objetivos, considerado, fundamentalmente, a busca pelo lucro e/ou a maximização de resultados econômicos. Esse contexto demonstra também que "o território é uma produção social, procurando analisar os conflitos que se estruturam e as lutas que se travam em torno deste ambiente construído socialmente." (BRANDÃO, 2011, p. 3), "pois a História não se escreve fora do espaço e não há sociedade a-espacial. O espaço, ele mesmo, é social” (SANTOS, 1982, p. 1), portanto, história, tempo e espaço determinam a lógica deste sistema de produção.

Santos (1982; 1996), Harvey (1992), Vainer (2001; 2007), Ribeiro (2004), Limonad (2004), Pecqueur (2005; 2009), Brandão (2007; 2008; 2011; 2013) e Swyngedouw (2010) aceitam que existe uma relação contraditória entre a escala global, mundial, aqui também entendida como hegemonia, e as escalas regionais, nacionais, aqui entendidas como contra hegemonia.

De um lado há a globalização, "considerada como uma dinâmica homogeneizadora, insensível a nuances, aponta no sentido de uma visão de mundo onde as particularidades seriam eliminadas." (PECQUEUR, 2009, p. 80). E como movimento contra hegemônico, os mesmos autores percebem que o movimento dialético está no território, onde os sujeitos interagem e, levando em conta as diversas escalas, constroem seus territórios. A ação se dá no território, seja a dos sujeitos locais, seja a dos sujeitos globais. 
O movimento global atual está relacionado à transnacionalização dos capitais financeiros e dos grandes conglomerados e insere na dinâmica dos locais a homogeneização das ações e relações, e a partir das verticalizações, busca organizar e determinar os processos dos lugares. Ou seja, globaliza recursos, dinheiro, crédito, dívidas, padrões de produção e consumo (LIMONAD, 2004; RIBEIRO, 2004; SANTOS, 1996). Nesse contexto, glocalização é o termo de Swyngedouw (2010) que conceitua e pode ser utilizado para tratar da ação da escala global em nível local, a localização do global e a ação da escala local percebendo a escala global.

Para Vainer (2007), o capitalismo mundial promoveu (des)estruturação e (re)estruturação das nações e isso propiciou, nas últimas décadas, uma "espécie de conformada aceitação da fragmentação territorial que consagra a acomodação subordinada às formas contemporâneas da globalização." (VAINER, 2007, p. 10).

No entanto, como esse é o atual contexto, do sistema capitalista de produção, o esforço da análise e de prática está em entender, compreender e agir sob essas circunstâncias. E, concomitantemente, há o território com suas particularidades, "um tecido social heterogêneo e um espaço onde a diversidade impera" (LIMONAD, 2004, p. 54). São os sujeitos que, através de suas relações sociais e articulados em diversas escalas, constroem a dinâmica de cada território. "Cada período é portador de um sentido, partilhado pelo espaço e pela sociedade, representativo da forma como a história realiza as promessas da técnica." (SANTOS, 1996, p. 111).

O território é a arena da oposição entre o mercado - que singulariza com as técnicas da produção, a organização da produção, a "geografia da produção" e a sociedade civil - que generaliza - e desse modo envolve, sem distinção, todas as pessoas. Com a presente democracia de Mercado, o território é suporte de redes que transportam as verticalidades, isto é, regras e normas egoísticas e utilitárias (do ponto de vista dos atores hegemônicos), enquanto as horizontalidades levam em conta a totalidade dos atores e das ações (SANTOS, 1996, p. 175).

Ou seja, o possível espaço mediador entre local e global é a região, enquanto forma de organização, articulação dos sujeitos para a construção, essa não considerada enquanto evolução, mas, sim, enquanto construção, desconstrução e reconstrução das relações dos sujeitos, ou seja, "a região constrói-se a partir da ação de distintos agentes em múltiplas escalas articuladas que de certa forma encontram um rebatimento em práticas e processos sócio-espaciais histórica e geograficamente localizados." (LIMONAD, 2004, p. 58).

Assim, os territórios possibilitam a construção de sistemas de inovações regionais, a prevalência de aspectos de formação histórica, cultural, social, que tornam os 
territórios particulares. Nestas condições, "o desenvolvimento territorial designa todo processo de mobilização dos atores que leve à elaboração de uma estratégia de adaptação aos limites externos, na base de uma identificação coletiva com uma cultura e um território." (PECQUEUR, 2005, p. 12). E são os diversos territórios construídos que conformam as escalas de ação, enquanto categoria prática. Em suma, considerando a relação dialética global e regional, a guinada está na percepção de que o desenvolvimento se dá a partir das ações nos territórios, da formação da região através do processo de regionalização de cada território. E é nestas condições que se consolida a relação dialética entre o todo e as partes, ou seja,

[...] modo de produção, formação social, espaço - essas três categorias são interdependentes. Todos os processos que, juntos, formam o modo de produção (produção propriamente dita, circulação, distribuição, consumo) são histórica e espacialmente determinados num movimento de conjunto, e isto através de uma formação social. [...] Os modos de produção tornam-se concretos sobre uma base territorial historicamente determinada. Deste ponto de vista, as formas espaciais seriam uma linguagem dos modos de produção. Daí, na sua determinação geográfica, serem eles seletivos, reforçando dessa maneira a especificidade dos lugares (SANTOS, 1982, p. 4).

O processo de construção do desenvolvimento é histórico e espacial e a formação sócio-espacial, a partir das particularidades, ao interagir dialeticamente com o processo verticalizador da globalização determina a sentido de cada região.

Portanto, "o território é, de fato, como nós vimos, o resultado de uma criação realizada pelos próprios atores" (PECQUEUR, 2009, p. 99) e "para tanto, podemos afirmar que o desenvolvimento se faz onde se encontram os agentes (!) e não em um espaço abstrato" (PECQUEUR, 2009, p. 100), acrescentando-se que "las configuraciones escalares son el resultado de procesos socio-espaciales que regulan y organizam las relaciones del poder social." (SWYNGEDOUW, 2010, p. 49).

Para Bonnal; Cazella; Delgado (2012, p. 5) "o território é um lugar delimitado para o exercício do poder” (BONNAL; CAZELLA; DELGADO, 2012, p. 5), onde se destacam as estratégias de atuação dos atores da sociedade civil, setor privado e do próprio Estado. No entanto, não podemos nos limitar a esses, porque somente perceber uma sociedade civil é errôneo, pois destacam Lavalle (2003; 2011), Houtzager, Lavalle, Acharya (2004) que a sociedade civil é heterogênea, concreta e construída socialmente.

Assume-se que há territórios, sejam estes nações ou regiões, que pretendem e irão se incluir nesta lógica financeira internacional, com o objetivo de crescer nestas condições, e, também, que há territórios que poderão assumir um papel contra hegemônico, com ações e reações diferenciadas. 
Nestas condições, a arena, como citada por Brandão (2011) e aqui enfatizada no conceito de Santos (1996), é a que explicita o movimento dialético da superestrutura contra a estrutura, superestrutura enquanto sistema capitalista de produção e estrutura enquanto escala de ação, escala construída socialmente, politicamente e historicamente por seus atores.

O que não se pode negligenciar é que existem fatores endógenos que possibilitam ou não a ação no território, mas que, possivelmente, são muito maiores os fatores externos que influenciam o território do que os que aqueles considerados na ação do espaço. O espaço é construído quando se percebem as interações de todas as escalas e como cada uma pode interferir na outra: quando se relacionam, quando deixam de se relacionar. "Muitos trabalhos negligenciam que há complexas hierarquias inter-regionais e o comando maior desses processos, geralmente, está fora do espaço sob análise.” (BRANDÃO; COSTA; ALVES, 2006, p. 198). Assim, após explicitar a relação dialética entre o movimento global e a região, o artigo contextualiza a formação teórica e a história da região e como esta é resultado da regionalização do território.

\section{A construção da região: território e regionalização}

A construção do conceito de região adquire relevância em fins do século XIX. Lencioni (2001) afirma que para La Blache (1845-1918) a base da construção deste conceito é o gênero de vida, resultado de uma relação dos grupos humanos com o lugar que habitam, os modos de vida que se constroem durante muito tempo. Portanto, no período neocolonialista, a missão civilizatória destes povos com gêneros de vida ditos avançados era levar para povos menos avançados seu gênero de vida. Para este autor, a superfície terrestre era um mosaico de regiões dadas e caberia ao investigador identificá-las e descrevê-las, a partir de uma compreensão positivista.

Já para Hettner (1859-1941), a região é uma construção do pesquisador, postulando que "os limites regionais são provenientes de um exercício intelectual, uma construção intelectual do pesquisador." (LENCIONI, 2001, p. 190). A região, nestas condições, é resultante da pesquisa. Assim, "enquanto para La Blache a região se evidencia na paisagem, para Hettner ela não é autoevidente. Os limites regionais são provenientes de um exercício intelectual, uma construção intelectual do pesquisador." (LENCIONI, 2001, p. 190).

A partir dos anos 60, segundo Benko (1999), são construídas as concepções mais conhecidas de região. São concepções diversas que indicam aspectos diferenciados, ou seja, algumas percebem a região homogênea - de inspiração agrícola -, outros, a região polarizada, de inspiração industrial; e, por fim, a região 
plano ou de programa - i.e., de implementação de políticas públicas, administrativas, de interesse de empresas -, concebida para a ação.

Nos anos 70, as discussões sobre o desenvolvimento regional têm "uma verdadeira explosão de escritos. [...]. A construção de uma nova teoria começa muitas vezes pela critica, fundada na insatisfação sentida relativamente às teorias 'tradicionais' anteriores." (BENKO, 1999, p. 85). Pecqueur (2009, p. 82) corrobora essa afirmação e sinaliza que a emergência da discussão territorial ocorre no período pós-fordista, ou seja, a mesma percepção demarcada nos anos 70 , assumindo que no período fordista o território não era percebido e que este "aparece hoje sob múltiplas formas, em função dos contextos produtivos onde ele se manifesta".

No entanto, enfatiza Benko (1999, p. 93) que "o problema é que as regiões não são homogêneas entre si, e as nações ainda menos". E, mais, para Lencioni (2001, p. 201) "é importante deixar bem claro que as perspectivas acerca da noção de região não são falsas nem verdadeiras". Ou seja, existe a clara percepção de que a região é resultado de formação particular de cada território. Mas território enquanto relação entre sociedade e ambiente, sociedade e natureza, e este como o espaço de construção das regiões, em seus arranjos territoriais particulares. Assim, o território é resultado da

[...] apropriação do espaço pela ação social de diferentes atores. [...] o conceito de território incorpora o jogo de poder entre os atores que atuam num espaço. Como resultado desse jogo de poder, se define uma identidade relacionada a limites geográficos, ou ao espaço determinado (FLORES, 2006, p. 4).

Com base no exposto, território "é um espaço geográfico construído socialmente, marcado culturalmente e delimitado institucionalmente." (CIRAD-SAD apud FLORES, 2006, p. 7).

Nesta relação dos espaços estruturados e agentes, a diversidade deve ser vista enquanto potencialidade, considerando que as desigualdades são próprias das regiões, ou seja, que a heterogeneidade é intrínseca aos territórios concretamente constituídos. Em suma, "a noção de regionalização é nitidamente polissêmica" (RIBEIRO, 2004, p. 198), com múltiplos sentidos, apoiados além da existência da região enquanto tal, a capacidade produtiva desta, além dos aspectos ideológicos, paisagem, valores culturais, critérios políticos e científicos:

[...] a região seria uma resultante da construção histórica desta complexa coerência, construída a partir da dialética articulação (enfrentamento) de distintos processos sociais, que tende a conferir características específicas a um determinado espaço social, e a expressar os distintos 
interesses dos agentes e atores sociais envolvidos (LIMONAD, 2004, p. $55)$.

Ou seja, regionalização de fato, enquanto construção histórica, "da gênese e da estruturação das regiões, depende da reconstrução histórica dos múltiplos processos que movimentaram e limitaram a ação hegemônica." (RIBEIRO, 2004, p. 194).

A construção social se dá a partir das práticas sociais de cada território, sendo que essas dependem da construção e de cada comunidade. "Desta maneira, a regionalização como fato encontra-se vinculada aos jogos dinâmicos da disputa de poder, inscritos nas diferentes formas de apropriação (construção e uso) do território.” (RIBEIRO, 2004, p. 195).

Assim, propõe-se

o retorno a uma visão "territorial" do desenvolvimento, preconizando ações de âmbito local, valorizando os recursos locais [leia-se regional], com a participação da população, e integrando dados dos vários meios (econômicos, sociais, culturais e políticos) (BENKO, 1999, p. 85).

Considera-se o território como espaço construído pelos atores sociais, com sentimento de pertencimento e ação coletiva. O que faz a ação coletiva é o capital social de determinado território. É este que estabelece o potencial de desenvolvimento do território, ligado a fatores histórico-culturais, e aqui se incluem fatores sociais, ambientais, políticos e éticos, capital este que pode ser construído e maximizado nos territórios. Assim, "[...] capital social pode ser construído, a partir de uma inter-relação entre o Estado e a sociedade local." (FLORES, 2006, p. 27).

Capital social aqui entendido como o conjunto de cidadãos que, confiantes uns nos outros, produzem e conduzem a sociedade na qual estão inseridos para uma condição mais eficiente de desenvolvimento. Tratam-se de resultados positivos para o desenvolvimento que não existiriam em diferentes condições, ou seja, são as "características da organização social, como confiança, normas e sistemas, que contribuem para aumentar a eficiência da sociedade, facilitando as ações coordenadas.” (PUTNAM, 1996, p. 177). Talvez, nestas condições, não seja possível um único modelo de desenvolvimento regional e, sim, múltiplos modelos de desenvolvimento regional, construídos regionalmente.

Considerando que o território é resultado da ação dos atores, existem possíveis e diferenciadas formas de promoção, ou de ausência de promoção, do desenvolvimento. No entanto, se levado em conta que é possível - a partir das particularidades regionais, sendo estas culturais, sociais, ambientais, políticas, 
econômicas - promover o desenvolvimento das regiões, a construção social dos atores, tanto hegemônicos como contra hegemônicos, dos indivíduos e dos grupos formais e informais, conformará um desenvolvimento, sendo este intencional ou não.

Nestas condições, é apresentado o Vale do Taquari e as prioridades estratégicas são identificadas por parte dos sujeitos que atuam na região.

\section{O Vale do Taquari e as prioridades estratégicas regionais}

Compreender os aspectos de formação de um território vai além de identificar seus principais indicadores, mas é fundamental percebê-los de forma integrada às discussões prioritárias regionais, ou seja, compreender de qual território se trata e como os sujeitos se articulam, definindo aquelas que são prioridades regionais, é pressuposto para analisar sua relação dialética com o movimento global.

Enquanto território, o Vale do Taquari é compreendido como

[...] uma região composta atualmente por 36 municípios, segundo a área de abrangência dos COREDES - Conselhos Regionais de Desenvolvimento do Estado do Rio Grande do Sul. Localiza-se na região central do Rio Grande do Sul e dista em média 150 quilômetros de Porto Alegre, integrando a "região funcional 2", juntamente com o COREDE Vale do Rio Pardo (CODEVAT, 2009, p. 16).

A região possui $1,71 \%$ da área total do estado e, em 2011, demonstrava ser responsável por 3,23\% do PIB, com valor de $\mathrm{R} \$ 8.510 .190 .000,00$, e PIB per capita de $\mathrm{R} \$ 25.798,00$ e 3,07\% da população, totalizando 329.258 pessoas. Uma região que foi responsável, em 2011, por 30\% da produção de frangos, 15\% da produção de suínos e $9 \%$ da produção leiteira estadual (FEE, 2014). Parcela significativa do setor industrial está vinculada ao agronegócio e a produção de alimentos. Além do mais, destaca-se na produção de móveis, confecções, entre outros. Os indicadores Índice de Desenvolvimento Sócio-Econômico (IDESE) e Índice de Desenvolvimento Humano (IDH), em 2010, são 0,765 e 0,727, respectivamente (FEE, 2014; IBGE, 2014).

Quando enfatizados os programas de transferência de renda, no caso do Programa Bolsa Família, que atende famílias com rendimento médio mensal abaixo de $\mathrm{R} \$$ 70,00, o Vale do Taquari, teve 6.854 famílias atendidas em 2012. Assim, observando a partir deste indicador, se considerarmos o número de domicílios de 112.127 (Censo, 2010), pouco mais de 6\% dos domicílios recebe esse benefício. Comparando esse dado, nas mesmas condições, com a estatística estadual, esse percentual é de quase 13\%, ou seja, há 463.519 famílias beneficiadas para uma 
quantidade de domicílios de 3.599.263. Assim, pode-se inferir que o Vale do Taquari, comparativamente a média estadual, possui metade dos habitantes atendidos por programas de transferência de renda (IBGE, 2014).

Considerando a disponibilidade de dados municipais ou regionais, pode-se incluir informações acerca do saneamento no ano de 2010. Este amplia a visão e a relação sociedade e meio ambiente. Em se tratando de abastecimento de água, a região apresenta $15 \%$ da população desprovida de atendimento pela rede geral de água, ou seja, são 16.496 domićlios que utilizam poço ou nascente para abastecimento doméstico de água.

Praticamente 93\% do lixo nos municípios é coletado, o restante é jogado, enterrado ou queimado. No entanto, estes $93 \%$ coletados são, na grande maioria, destinados ao município de Minas do Leão, sem nenhum tipo de separação e/ou reutilização através de reciclagem. Em se tratando de esgotamento, somente 11\% dos domicílios da região estão ligados a uma rede geral de esgoto, sendo que a maioria, $57 \%$, possui fossa séptica, e $30 \%$ possui fossa rudimentar, e em torno de 5\% dos domicílios não possui banheiro ou se utiliza de vala (CODEVAT, 2014; FEE, 2014). Ainda, para não tratar especificamente do saneamento nas áreas urbanas, no meio rural há uma concentração elevada na criação de animais, conforme exposto anteriormente e com baixa adequação para o correto manejo e possível reutilização dos dejetos orgânicos.

O tema aqui levantado é tão saliente uma vez que, conforme diagnosticado no Plano da Bacia Hidrográfica Taquari-Antas, 35\% das doenças de veiculação hídrica do estado do Rio Grande do Sul ocorre nesta Bacia. Também, segundo o Plano, todos os pontos analisados neste trecho da bacia resultaram em classes de água 3 ou 4, no parâmetro da Resolução do Conselho Nacional de Meio Ambiente - CONAMA ${ }^{2}$ (SEMA, 2012).

Com o objetivo de compreender a relação do Vale do Taquari com o movimento global e tentar inferir quais temas a participação social considera estratégicos, foram levantados três diferentes tipos de informações geradas por esta região. Primeiro, os macro-objetivos identificados no Planejamento Estratégico Regional, em 2009.

Este propôs e enfatiza que

[...] trata-se de uma visão parcial da região do Vale do Taquari, construída por seus representantes, que propõe ações, nas mais diversas áreas estudadas e discutidas, a serem implementadas no Vale, buscando $\mathrm{o}$ atendimento à visão e vocação determinadas. Construído e

\footnotetext{
${ }^{2}$ O Conselho Nacional de Meio Ambiente - CONAMA, determina, via Resolução 357/2005, as classes de água, sendo elas avaliadas de 1 a 4, da melhor para a pior qualidade de água.
} 
consolidado, coletivo e participativo, o Planejamento Estratégico do Vale do Taquari conta com o apoio e retrata a participação e articulação coletiva em prol do desenvolvimento regional (CODEVAT, 2009, p. 5).

Como segundo tipo de informação, constam as Prioridades Estratégicas oriundas da Participação Popular e Cidadã, nos anos de 2012, 2013, 2014, anos em que estas ocorreram. As prioridades estratégicas são os temas relevantes, indicativos para as ações do Governo do Estado do Rio Grande do Sul nas regiões. No entanto, essas prioridades devem seguir as determinações das Diretrizes e áreas temáticas da Participação Popular e Cidadã (SEPLAG, 2014).

Observe-se que a Participação Popular e Cidadã inicia em 1998 no Estado do Rio Grande do Sul, instituída na Lei Estadual n.11.179, de 25 de junho de 1998, e introduz uma consulta popular "através da qual a população deveria indicar, com base em listas elaboradas pelos Coredes, com orientação da Secretaria da Coordenação e Planejamento, alguns dos investimentos a serem realizados pelo Estado em cada região." (BANDEIRA, 2011, p. 225). Esse processo ocorre até os dias atuais e no ano de 2012 teve ampliação na consulta à população. Seu nome atual é Participação Popular e Cidadã e, além de listar projetos a serem eleitos nas regiões e disputarem recursos previamente disponibilizados pelo Estado, há um campo de indicação das prioridades estratégicas.

No terceiro tipo de informação, há uma lista de prioridades regionais, aprovadas no Conselho de Desenvolvimento do Vale do Taquari, em Assembleia Geral ${ }^{3}$ realizada no mês de março de 2014, que indicou temas prioritários para os candidatos a cargos eletivos na região naquele pleito eleitoral. O documento busca demonstrar "a visão estratégica da região a médio e longo prazo", subsidiando aqueles que concorrem a cargos eletivos para saberem o que "devem defender em termos de interesse do Vale do Taquari.” (CODEVAT, 2014, p. 1).

Assim, no Quadro 1 constam os macro-objetivos construídos no Planejamento Estratégico Regional, em 2009. São objetivos amplos e que levaram em conta quatro grandes áreas: econômica, estrutural, social e institucional.

\footnotetext{
${ }^{3}$ A Assembleia Geral do CODEVAT é composta por deputados com domicílio nesta região, por prefeitos, por presidentes das Câmaras de Vereadores, presidentes dos Conselhos Municipais de Desenvolvimento, reitores e presidentes de Fundações de Ensino Superior sediadas na região e um representante de cada entidade civil organizada, com domicílio no Vale do Taquari (CODEVAT, 2014).
} 


\section{Quadro 1 Macro-objetivos do Planejamento Estratégico Regional, 2009}

\begin{tabular}{|c|c|}
\hline \multirow{4}{*}{$\begin{array}{l}\text { Gestão } \\
\text { econômica }\end{array}$} & $\begin{array}{l}\text { Promover a agregação de valor às cadeias produtivas vinculadas ao } \\
\text { agronegócio, através de investimentos e incentivos, da busca à sua } \\
\text { complementação e sustentabilidade (econômica, social e ambiental), da } \\
\text { qualificação dos empreendimentos através de certificados de qualidade } \\
\text { e/ou registros de procedência e do estímulo aos negócios voltados a } \\
\text { pequenos e médios empreendimentos, baseados no associativismo } \\
\text { e/ou cooperativismo. }\end{array}$ \\
\hline & $\begin{array}{l}\text { Promover investimentos em cadeias produtivas alternativas às do } \\
\text { agronegócio, que possam também aproveitar as características } \\
\text { regionais. }\end{array}$ \\
\hline & $\begin{array}{l}\text { Promover o desenvolvimento a partir da inovação tecnológica, de } \\
\text { pesquisas, de patentes, de negócios inovadores, do empreendedorismo } \\
\text { e da qualificação da mão de obra, para maior inserção no mercado } \\
\text { globalizado e qualificação das empresas locais e dos produtos } \\
\text { regionais. }\end{array}$ \\
\hline & $\begin{array}{l}\text { Promover investimentos no turismo regional, utilizando-se dos } \\
\text { atrativos naturais/culturais para inserir a região neste mercado. }\end{array}$ \\
\hline \multirow{5}{*}{$\begin{array}{l}\text { Gestão } \\
\text { estrutural }\end{array}$} & $\begin{array}{l}\text { Promover a implementação de programas e projetos que possibilitem } \\
\text { o acesso de todos os municípios às tecnologias da informação, em se } \\
\text { tratando de telefonia fixa, móvel e internet. }\end{array}$ \\
\hline & $\begin{array}{l}\text { Promover projetos que viabilizem a implantação de sistemas que } \\
\text { qualifiquem a energia distribuída. }\end{array}$ \\
\hline & $\begin{array}{l}\text { Promover a implantação de sistemas e/ou programas para saneamento } \\
\text { (tratamento de esgotos, destinação de lixo, tratamento de resíduos e } \\
\text { tratamento de água) e redução da carga orgânica despejada nos } \\
\text { recursos hídricos, possibilitando, além da qualificação dos recursos } \\
\text { hídricos, melhoria nas condições ambientais e sociais regionais. }\end{array}$ \\
\hline & $\begin{array}{l}\text { Promover a qualificação da logística regional visando a melhor } \\
\text { exploração das potencialidades dos transportes rodoviário, ferroviário } \\
\text { e fluvial disponíveis e da localização privilegiada da região. }\end{array}$ \\
\hline & $\begin{array}{l}\text { Promover a implementação de programa de habitações populares para } \\
\text { prevenir a formação de centros habitacionais irregulares nos } \\
\text { municípios do Vale do Taquari. }\end{array}$ \\
\hline
\end{tabular}


(conclusão)

\begin{tabular}{|c|c|}
\hline \multirow{5}{*}{ Gestão social } & $\begin{array}{l}\text { Promover segurança pública de qualidade, suprindo seus órgãos com } \\
\text { recursos humanos, materiais e tecnológicos. }\end{array}$ \\
\hline & $\begin{array}{l}\text { Promover programas/projetos/ações que visem o atendimento de } \\
\text { saúde integral (preventiva e corretiva), atuando nas mais diversas } \\
\text { complexidades (baixa, média e alta). }\end{array}$ \\
\hline & $\begin{array}{l}\text { Promover a qualificação profissional e cidadã através da educação } \\
\text { formal, não formal e profissionalizante, vinculadas aos saberes } \\
\text { regionais. }\end{array}$ \\
\hline & $\begin{array}{l}\text { Promover programas/projetos/ações que visem a inserção/inclusão e } \\
\text { assistência social. }\end{array}$ \\
\hline & $\begin{array}{l}\text { Promover programas/projetos/ações que tratem das questões de } \\
\text { dependência química e drogadição. }\end{array}$ \\
\hline \multirow{4}{*}{$\begin{array}{l}\text { Gestão } \\
\text { institucional }\end{array}$} & $\begin{array}{l}\text { Promover espaços de construção da participação cidadã, de formação } \\
\text { de lideranças regionais e a ampliação da representatividade política e } \\
\text { classista em instâncias estaduais e federais. }\end{array}$ \\
\hline & $\begin{array}{l}\text { Promover a consolidação das relações interinstitucionais } \\
\text { locais/regionais. }\end{array}$ \\
\hline & Promover a revitalização de parcerias público-privadas. \\
\hline & Promover mecanismos de gestão nos municípios. \\
\hline
\end{tabular}

Fonte: Elaborado pela autora, a partir de CODEVAT (2009).

Nos Quadros 2, 3 e 4 constam as prioridades estratégicas para os anos de 2012, 2013, 2014, respectivamente, as quais compuseram a cédula de votação da Participação Popular e Cidadã no Vale do Taquari. Elas possuem as restrições consideradas a partir das Diretrizes do Processo, e, no entanto, são discutidas em todas instâncias regionais, desde as discussões na própria região, nas assembleias municipais, como na votação, momento em que todos os eleitores têm oportunidade de contribuir com suas percepções (SEPLAG, 2014).

Cabe salientar que na votação de 2012 participaram 34.543 eleitores, na de 2013, 30.003 eleitores, e na de 2014, 25.973 eleitores do Vale do Taquari. 
Quadro 2 Prioridades Estratégicas que compuseram a cédula de votação em 2012 e o total de votos por proposta

\begin{tabular}{|l|c|}
\hline \multicolumn{1}{|c|}{ Prioridades Estratégicas } & $\begin{array}{c}\text { Total de } \\
\text { votos }\end{array}$ \\
\hline $\begin{array}{l}\text { Saúde - Construção de Unidade de Atendimento da FUNDEF - } \\
\text { Fundação para Reabilitação das Deformidades Crânio-Faciais. }\end{array}$ & 16104 \\
\hline $\begin{array}{l}\text { Saúde - Construção de UTI - Unidade de Atendimento Intensivo, } \\
\text { junto ao Hospital Ouro Branco - Teutônia. }\end{array}$ & 15486 \\
\hline $\begin{array}{l}\text { Educação Superior - Estudos Técnicos de Infraestrutura } \\
\text { (duplicação das rodovias RS 128, RS 129, RS 130 e ponte sobre } \\
\text { Rio Taquari). }\end{array}$ & 11657 \\
\hline $\begin{array}{l}\text { Turismo, Esporte e Lazer - Programa de Desenvolvimento do } \\
\text { Turismo. }\end{array}$ & 10781 \\
\hline $\begin{array}{l}\text { Desenvolvimento Rural - Sanidade Animal. Programa de Controle } \\
\text { e Erradicação da Tuberculose e Brucelose. }\end{array}$ & 9289 \\
\hline
\end{tabular}

Fonte: Elaborado pela autora, a partir de CODEVAT (2014).

(continua)

Quadro 3 Prioridades Estratégicas que compuseram a cédula de votação em 2013 e o total de votos por proposta

\begin{tabular}{|l|c|}
\hline \multicolumn{1}{|c|}{ Prioridades Estratégicas } & $\begin{array}{c}\text { Total de } \\
\text { votos }\end{array}$ \\
\hline $\begin{array}{l}\text { Saúde - Programa de Regionalização da Saúde com foco na } \\
\text { descentralização, priorizando as microrregiões e atendimento em } \\
\text { diferentes especialidades no Vale do Taquari. }\end{array}$ & 17836 \\
\hline $\begin{array}{l}\text { Segurança Pública e Defesa Civil - Sistema de Vídeo } \\
\text { monitoramento Integrado de Segurança nos municípios do Vale } \\
\text { do Taquari. }\end{array}$ & 12261 \\
\hline $\begin{array}{l}\text { Educação Superior - Reestruturação e ampliação da UERGS no } \\
\text { Vale do Taquari. }\end{array}$ & 8506 \\
\hline $\begin{array}{l}\text { Desenvolvimento Rural - Programa de Defesa Agropecuária } \\
\text { (Sanidade Animal - Controle e Erradicação da Brucelose e } \\
\text { Tuberculose) no Vale do Taquari. }\end{array}$ & 6911 \\
\hline
\end{tabular}


(conclusão)

Cidadania, Justiça, Direitos Humanos e Políticas para as Mulheres

- Programa de Prevenção, Tratamento, Reinserção e Combate à Dependência Química no Vale do Taquari.

Fonte: Elaborado pela autora, a partir de CODEVAT (2014).

Quadro 4 Prioridades Estratégicas que compuseram a cédula de votação em 2014 e o total de votos por proposta

\begin{tabular}{|l|c|}
\hline \multicolumn{1}{|c|}{ Prioridades Estratégicas } & $\begin{array}{c}\text { Total de } \\
\text { votos }\end{array}$ \\
\hline Investimentos na Traumatologia no Vale do Taquari. & 15799 \\
\hline $\begin{array}{l}\text { Programa de Regionalização da Saúde com foco na } \\
\text { descentralização, priorizando as microrregiões e atendimento em } \\
\text { diferentes especialidades no Vale do Taquari. }\end{array}$ & 10299 \\
\hline $\begin{array}{l}\text { Aumento do Efetivo para os Órgãos de Segurança do Vale do } \\
\text { Taquari. }\end{array}$ & 9944 \\
\hline $\begin{array}{l}\text { Programa de Defesa Agropecuária (Sanidade Animal - Controle e } \\
\text { Erradicação da Brucelose e Tuberculose) no Vale do Taquari. }\end{array}$ & 8127 \\
\hline \begin{tabular}{l} 
Duplicação das ERS 129/130. \\
\hline
\end{tabular} & 7759 \\
\hline
\end{tabular}

Fonte: Elaborado pela autora, a partir de CODEVAT (2014).

Por fim, o Quadro 5 indica as prioridades discutidas no âmbito do Conselho e que serão encaminhadas aos candidatos a pleitos - deputados estaduais e federais, senadores e governador do Estado. 


\section{Quadro 5 Estratégias para o Desenvolvimento do Vale do Taquari - Prioridades encaminhadas aos candidatos a cargos eletivos em 2014}

1. Segurança pública: Aumentar o efetivo da Brigada Militar e Polícia Civil.

2. Infraestrutura: Planos de Mobilidade Urbana e Regional e Projetos de Infraestrutura:

Duplicações das ERS 129/130;

Duplicação da BR-386, de Lajeado a Iraí;

Reativação do Aeródromo Regional, localizado em Estrela;

Reativação do Porto em Estrela;

Interligação ferroviária, Ferrovia Norte-Sul.

3. Saneamento básico: Investir em Programas de Saneamento.

4. Educação: Ampliar a atuação de escolas em tempo integral.

5. Saúde: Tratar regionalmente o tema da traumatologia.

6. Energia elétrica: geração e distribuição de energia elétrica.

7. Enchentes: Ampliar e qualificar o sistema de alertas de cheias e obras de controle de enchentes.

8. Agricultura: Reaproveitar os dejetos orgânicos.

9. Infraestrutura turística - Asfaltamento da Rodovia que interliga Muçum e Santa Tereza.

10. Programa de Prevenção, Tratamento, Reinserção e Combate à Dependência Química no Vale do Taquari.

Fonte: Elaborado pela autora, a partir de Vale do Taquari (2014).

Os documentos apresentados discorrem sobre as prioridades regionais, considerando a articulação da representação das entidades regionais e da participação direta da população nas assembleias municipais da Participação Popular e Cidadã e na votação deste processo.

São documentos dos anos de 2009, no caso do Planejamento Estratégico; de 2012, 2013, 2014, no caso das prioridades estratégicas da Participação Popular e Cidadã; e de 2014, no caso das Estratégias para o Desenvolvimento do Vale do Taquari, o que também traduz as articulações regionais dos últimos anos. 


\section{Desenvolvimento regional a partir das Estratégias Prioritárias do Vale do Taquari}

As particularidades regionais são as que podem possibilitar o desenvolvimento na perspectiva territorial, enfatizando a dinâmica e a diversidade de cada região, e, nestas condições, promover o desenvolvimento regional.

A escala regional é a que possibilita o avanço na perspectiva da promoção do desenvolvimento sustentável, ou seja, é na perspectiva da regionalização do território, considerando as particularidades, diversidades, que se conformam e possibilitam a "construção de novas horizontalidades que permitirão, a partir da base da sociedade territorial, encontrar um novo caminho que se anteponha à globalização perversa e nos aproxime da possibilidade de construir uma outra globalização (ETGES, 2005, p. 54).

Nestas condições, considerar a região enquanto formação de um território particular sustentável que se contrapõe ao movimento global é perceber que a "desigualdade, portanto, é intrínseca ao modo de produção capitalista, e o seu desenvolvimento, por consequência, também é desigual, em qualquer dimensão do espaço geográfico.” (ETGES; DEGRANDI, 2013, p. 4).

Se observarmos os documentos produzidos por esta região, citados neste artigo, ou seja, o Planejamento Estratégico em 2009, as prioridades elencadas e votadas pela população na participação direta e as prioridades consideradas estratégicas definidas em Assembleia, em 2014, percebe-se que naqueles documentos que dão conta generalizadamente do processo, várias áreas são inseridas, mas no caso das prioridades elencadas na Participação Popular e Cidadã, e que possuem um caderno de diretrizes como regramento, essas ficam mais restritas. No entanto, somente nesta há a participação direta; nas outras formas a decisão se dá na forma da democracia representativa, ou seja, sujeitos vinculados às instituições e entidades regionais.

Observando o planejamento e os macro-objetivos identificados, estes possuem temas da gestão econômica, estrutural, social, institucional, dando conta de uma diversidade maior de áreas a serem atendidas. Mas, analisando-se mais detalhadamente, nos macro-objetivos vinculados à área econômica, é relevante observar que em alguns momentos são enfatizadas as características regionais, e, em outros, se salienta a necessidade de inserção no mercado global. Prioritariamente, as propostas percebem a região como passível de ser competitiva, inovadora e empreendedora, porque até mesmo o objetivo voltado ao turismo demonstra a percepção de inserir a região no mercado, sem determinar claramente como isso ocorreria. 
Quando analisados os macro-objetivos a partir da gestão estrutural, é explícito que as questões de saneamento urbano e rural visam "qualificação dos recursos hídricos, melhoria nas condições ambientais e sociais regionais." (CODEVAT, 2009 , p. 250). De igual forma pode ser considerado o objetivo de implementação de programas de habitação regional. No entanto, o acesso à tecnologia, à energia e logística regional priorizam aspectos competitivos regionais, buscando atrelar o Vale do Taquari ao movimento competitivo global.

Quando analisados os objetivos voltados a gestão social, o entendimento se dá a partir da segurança pública, saúde integral, qualificação profissional e cidadã, assistência social e programas que se voltam para a prevenção e a supressão da dependência química. Estes demonstram a preocupação com a qualidade de vida da sociedade regional, com atendimento das questões básicas acerca dos aspectos sociais.

Já, quando percebidos os aspectos da gestão institucional, demonstra uma percepção regional da necessidade de "promover espaços de construção da participação cidadã, de formação de lideranças regionais e a ampliação da representatividade política e classista em instâncias estaduais e federais" e "promover a consolidação das relações interinstitucionais locais/regionais." (CODEVAT, 2009, p. 254). Além de trazer a necessidade de revitalização parcerias dos setores públicos e privados e qualificar a gestão pública municipal.

No caso do Planejamento Estratégico Regional, podemos inferir que a lógica pretende levar em conta os aspectos da qualidade de vida da população e da competitividade regional. Esta qualidade de vida é medida e mensurada a partir das percepções generalistas e de senso comum, em se tratando das condições de educação, saúde, renda, segurança, saneamento, habitação e assistência social. E são identificados aspectos que dão conta da competitividade regional, com o objetivo de inseri-la no movimento econômico mundial, com infraestrutura dos modais de transporte, de energia, de comunicações, que viabilizem empreendimentos inovadores e competitivos.

Já, quando avaliadas as Prioridades Estratégicas Regionais, percebe-se que, no ano de 2012, dos cinco temas prioritários, dois eram da área da saúde - os dois mais votados -, um dedicado à infraestrutura - o terceiro maior detentor de votos -, o quarto colocado sendo voltado para o Turismo, e o quinto foi percebido a partir do Desenvolvimento Rural, em se tratando de tema da Sanidade Animal.

No ano de 2013 novamente tem-se uma prioridade na área da saúde e novamente esta é a proposição mais votada. Seguindo a ordem de votação, o segundo foi na área da segurança e o terceiro na educação superior, no intento de viabilizar a Universidade Estadual do Rio Grande do Sul (UERGS). No mesmo ano, repete-se o quinto tema, o da Sanidade Animal.

No ano de 2014 os projetos parecem se repetir, porque os dois mais votados são da área da saúde, repetindo, em segundo lugar, a mesma prioridade de 2013. 
Como terceira proposição mais votada tem-se um projeto na área da segurança, sendo que retornou o item sanidade animal e, por fim, reafirmou-se a prioridade na infraestrutura rodoviária. Percebe-se que grandes temas, basicamente sociais, repetem-se nos três anos, com ênfase nas prioridades na saúde, sendo estas as mais votadas em todos os anos da consulta popular.

Por fim, quando avaliados os grandes temas encaminhados e as prioridades listadas nas "Estratégias para o Desenvolvimento do Vale do Taquari", os temas de segurança pública, infraestrutura, saneamento, saúde, energia, dejetos orgânicos oriundos da agricultura, infraestrutura turística e programa de prevenção e combate à drogadição repetem-se nos outros documentos. Somente dois são diferentes dos citados anteriormente, mas, ainda que de forma generalizada, já haviam sido abordados: educação voltada para escolas em tempo integral e sistema de alerta de cheias e obras de controle de enchentes.

Isso demonstra coerência nas diferentes construções regionais, desde aquelas mais participativas até as outras, as que discutem os temas regionais, a partir das representações. No entanto, todas deixam claras as indicações sociais de atendimento das necessidades consideradas básicas, as de saúde, educação, assistência social, assim como a percepção das entidades representativas da lógica de integração global.

Levando em conta o que enfatiza Etges (2001; 2005)

[...] o processo de globalização, que vem reconfigurando os territórios mundo afora na atualidade não se resume a uma única face. Há pelo menos duas faces: a da perversidade do processo em si, expressa na territorialização dos interesses dos segmentos hegemônicos, e a da oportunidade, que se apresenta aos atores regionais, quando se apropriam de conhecimentos que lhes permitem reagir, superar a passividade (ETGES, 2005, p. 51).

Nestas condições, o Vale do Taquari parece tentar viabilizar o seu desenvolvimento regional, ora buscando integrar-se ao processo hegemônico, ora buscando as particularidades regionais. Demonstra ter consciência de que são os atores regionais que podem contribuir para este desenvolvimento, mas que, no entanto, ainda se percebe basicamente na inserção no mercado global. Está explícito isso desde a percepção da ênfase no agronegócio, considerando as principais cadeias produtivas (frangos, suínos, leite) - estando essas duas primeiras claramente inseridas no contexto global -, até as possibilidades das novas cadeias produtivas, os projetos de infraestrutura e de logística, baseados nos projetos de inovação e empreendedorismo. 


\section{Considerações finais}

Em seu planejamento estratégico, o Vale do Taquari definiu sua visão estratégica, pela qual se propõe a "ser uma região de referência no País em qualidade de vida, baseada em valores humanos e sustentabilidade ambiental, com fortes e duradouros relacionamentos interinstitucionais.” (CODEVAT, 2009, p. 247).

As vocações pretendem ressaltar os potenciais regionais. Assim, "o Vale do Taquari possui uma economia diversificada, inovadora e empreendedora, voltada à educação como fundamento nas redes de formação, à saúde integral e preventiva, à preservação da segurança e da ordem pública e ao turismo e lazer." (CODEVAT, 2009, p. 247).

Por fim, os valores ressaltados são:

valores familiares, comunitários, de formação histórico-cultural, de respeito pelos saberes populares; valores voltados para o trabalho, honestidade, ética, compromisso e organização; valores da percepção do público como sendo de todos; valores de identificação onde cada cidadão sente ser parte da construção do Vale do Taquari; e, valores de respeito às autoridades, às leis e a ordem pública (CODEVAT, 2009, p. 247).

Percebe-se que as prioridades apresentadas nos três documentos aqui citados levam em conta a visão, as vocações e os valores identificados por esta região, e que há coerência nas discussões e construções regionais ao longo do tempo. No entanto, elas não demonstram claramente se essas são particularidades regionais ou condições gerais de atendimento da qualidade de vida da sociedade. Além do mais, aquelas prioridades parecem demonstrar que esta região pretende compararse a outras e promover o seu desenvolvimento a partir das percepções mais gerais, alinhadas à construção dos conglomerados mundiais.

No entanto, nos parece que o que se faz necessário é tratar de forma desigual os desiguais - que as políticas públicas devam fortalecer as características destas sociedades, para possibilitar o empoderamento e o desenvolvimento regional. Por fim, deve-se levar em conta os aspectos contraditórios, fortalecer e promover as horizontalidades através das forças centrípetas regionais, possibilitando o desenvolvimento regional e consolidando a percepção de que não há a possibilidade de comparação de desenvolvimento regional, pois as regiões promovem o desenvolvimento de forma desigual e possuem formações históricoculturais desiguais, o que promove um desenvolvimento regional particular e próprio de cada região. 
Não nos parece que o Vale do Taquari possa ser considerado uma das regiões mais atreladas ao mercado mundial, à lógica da globalização e da homogeneização a partir dos grandes conglomerados. No entanto, o olhar sobre as particularidades regionais ainda foca basicamente os aspectos da qualidade de vida da população, o que nos parece primordial, mas avançar para os aspectos institucionais poderá empoderar esses grupos. Propõe-se, minimamente, ter conhecimento da lógica dialética regional e global para, ao se apropriar desta diversidade, proporcionar um desenvolvimento regional para o Vale do Taquari.

\section{Referências}

ALVES, Alda Judith. A "revisão da bibliografia" em teses e dissertações: meus tipos inesquecíveis. Cadernos de Pesquisa, São Paulo, n. 81, mai., p.53-60, 1992.

BANDEIRA, Pedro Silveira. Uma experiência de institucionalização de regiões no Brasil: os Coredes do Rio Grande do Sul. In: DALLABRIDA, Valdir Roque (Org.). Governança territorial e desenvolvimento: descentralização políticoadministrativa, estruturas subnacionais de gestão do desenvolvimento e capacidades estatais. Rio de Janeiro: Garamond, 2011.

BAQUERO, Marcello. et al. Reflexões sobre a pesquisa nas ciências humanas. Barbarói, Santa Cruz do Sul, n. 2, p.17-32, mar., 1995.

BENKO, George. A ciência regional. Oeiras: Celta Editora, 1999.

BONNAL, Philippe; CAZELLA, Ademir Antonio; DELGADO, Nelson Giordano. Contribuições ao estudo do desenvolvimento territorial rural: reflexões metodológicas a partir do caso brasileiro. Revista Bibliográfica de Geografía y Ciencias Sociales. Universidade de Barcelona, v. XVII, n., 1002, nov., 2012.

BRANDÃO, Carlos Antônio. A. O campo da economia política do desenvolvimento: o embate com os "localismos" na literatura e nas políticas públicas contemporâneas. In: BRANDÃO, Carlos Antônio. Território e desenvolvimento: as múltiplas escalas entre o local e o global. Campinas/SP: Unicamp, 2007, p. 35-55.

- Pactos em territórios: escalas de abordagem e ações pelo desenvolvimento. Organizações \& Sociedade, v. 15, n. 45, p. 145-157, abr./jun.2008. 
. Visões teóricas sobre desenvolvimento regional e a questão das escalas (mundial, nacional, subnacional e local) nas políticas regionais contemporâneas. Curso Territorialidade e Políticas Públicas no Brasil. ENAP. Brasília, mai., 2011.

Transversalidade, multiescalaridade e os desafios da legitimação das políticas regionais no Brasil. Revista Política e Planejamento Regional, p. 3240, mar., 2013.

BRANDÃO, Carlos Antônio; COSTA, Eduardo José Monteiro da; ALVES, Maria Abadia da Silva. Construir o espaço supralocal de articulação socioprodutiva e das estratégias de desenvolvimento: os novos arranjos institucionais. In: DINIZ, Clélio Campolina; CROCCO, Marco (Org.). Economia regional e urbana: contribuições teóricas recentes. Belo Horizonte: Editora UFMG, p. 195-224, 2006.

CODEVAT. Conselho de Desenvolvimento do Vale do Taquari. Disponível em: http://www.codevat.org.br/site/home. Acesso em: 12 jun. 2014.

. Planejamento Estratégico Regional do Vale do Taquari. Lajeado: CODEVAT, 2009.

ETGES, Virgínia Elisabeta. A região no contexto da globalização: o caso do Vale do Rio Pardo. In: VOGT, Olgário; SILVEIRA, Rogério. Vale do Rio Pardo: (re)conhecendo a região. Santa Cruz do Sul: Edunisc. 2001.

- Desenvolvimento Regional sustentável: o território como paradigma. REDES, Santa Cruz do Sul, v. 10, n. 3, p. 47-55, set./dez., 2005.

ETGES, Virgínia Elisabeta; DEGRANDI, José Odim. Desenvolvimento regional: a diversidade regional como potencialidade. Revista Brasileira de Desenvolvimento Regional, Blumenau, v. 1, n. 1, p. 85-94, abr., 2013.

FEE. Fundação de Economia e Estatística do Estado do Rio Grande do Sul. Disponível em: http://www.fee.rs.gov.br. Acesso em: 12 jun. 2014.

FLORES, Murilo. A identidade cultural do território como base de estratégias de desenvolvimento: uma visão do estado da arte. 2006. Disponível em: http://www.fidamerica.cl/admin/docdescargas/centrodoc/centrodoc 236. pdf. Acesso em: 20 mar. 2014.

GIL, Antônio Carlos. Métodos e técnicas de pesquisa social. São Paulo: Atlas, 1999. 
HARVEY, David. A Transformação político-econômica do capitalismo do final do século XX. In: HARVEY, David. Condição pós-moderna: uma pesquisa sobre as origens da mudança cultural. São Paulo: Loyola, 1992.

HOUTZAGER, Peter P.; LAVALlE, Adrián Gurza; ACHARYA, Arnab. Atores da sociedade civil e atores políticos - Participação nas novas políticas democráticas em São Paulo. In: AVRITZER, Leonardo. Participação em São Paulo. São Paulo: UNESP, 2004 (no prelo).

IBGE. Instituto Brasileiro de Geografia e Estatística. Disponível em: http://www.ibge.com.br/home. Acesso em: 12 jun. 2014.

LAVALLE, Adrián Gurza. Sem pena nem glória: o debate sobre a sociedade civil nos anos 1990. Novos Estudos, n. 66, jul., 2003.

O estatuto político da sociedade civil: evidências da Cidade do México e de São Paulo. Textos para Discussão - CEPAL/IPEA, n. 28, 2011.

LENCIONI, Sandra. Região e geografia - a noção de região no pensamento geográfico. In: CARLOS, Ana Fani Alessandri. Novos caminhos da geografia. São Paulo: Contexto, 2001.

LIMONAD, Ester. Brasil, século XXI - regionalizar para que? Para quem. In: LIMONAD, Ester et al. Brasil Século XXI - por uma nova regionalização. São Paulo: Max Limonad, 2004.

PECQUEUR, Bernard. O Desenvolvimento territorial: uma nova abordagem dos processos de desenvolvimento para as economias do Sul. Revista Raízes, Campina Grande, v. 24, ns. 1 e 2, p. 10-22, jan./dez., 2005.

. A guinada territorial da economia global. Revista Política \& Sociedade, n. 14, p. 79-105, abr., 2009.

PRODANOV, Cleber Cristiano e FREITAS, Ernani Cesar de. Metodologia do trabalho científico [recurso eletrônico]: métodos e técnicas da pesquisa e do trabalho acadêmico. 2. ed. Novo Hamburgo: Feevale, 2013.

PUTNAM, Robert. Comunidade e Democracia. Rio de Janeiro: Fundação Getúlio Varas, 1996.

RIBEIRO, Ana Clara T. Regionalização: fato e ferramenta. In: LIMONAD, Ester. et al. Brasil Século XXI - por uma nova regionalização. São Paulo: Max Limonad, 2004. 
SANTOS, Antônio Raimundo dos. Metodologia científica: a construção do conhecimento. 7. ed. Rio de Janeiro: Lamparina, 2007.

SANTOS, Milton. Sociedade e espaço: a formação social como teoria e método. Espaço e Sociedade. Petrópolis: Vozes, 1982.

Hucitec, 1996.

A natureza do espaço - técnico e tempo, razão e emoção. São Paulo:

SEMA. Plano da Bacia Hidrográfica Taquari-Antas. 2012. Disponível em: http://www.taquariantas.com.br. Acesso em: 5 jun. 2014.

SEPLAG. Secretaria de Planejamento, Gestão e Participação Cidadã do Estado do Rio Grande do Sul. Disponível em: http://www.seplag.rs.gov.br. Acesso em: 12 jun. 2014.

SWYNGEDOUW, Erik. ¿Globalización o glocalización? Redes, territórios y reescalamiento. In: FERNÁNDEZ, Victor Ramiro e BRANDÃO, Carlos Antônio (orgs.). Escalas y políticas del desarrollo regional: desafíos para América Latina. UNL/FCE: Mino e Dávila Editores, 2010.

VAINER, Carlos Bernardo. As escalas do poder e o poder das escalas: o que pode o poder local? In: Encontro Nacional da Anpur, 9, 2001, Rio de Janeiro. Anais... Ética, Planejamento e Construção Democrática do Espaço; v. 1. Rio de Janeiro: Anpur, 2001, p. 140-151.

- Planejamento Territorial e Projeto Nacional: Os desafios da Fragmentação. Revista Brasileira de Estudos Urbanos e Regionais, v. 9, n.1, mai., 2007.

VALE DO TAQUARI. Estratégias para o Desenvolvimento do Vale do Taquari: 2015-2018. Vale do Taquari, 2014.

VERGARA, Sylvia Constant. Métodos de pesquisa em administração. São Paulo: Atlas, 2005.

Endereço para correspondência:

CintiaAgostini-cintia@univates.br

Av. Avelino Talini, 171, Bairro Universitário

95.900-000 Lajeado/RS, Brasil 